\title{
Does Arthroplasty Provide Better Outcomes Than Internal Fixation At Mid- and Long-term Followup? A Meta-analysis
}

\author{
Jin Jiang MD, PhD, Chen-hui Yang MD, Qiao Lin MD, \\ Xiang-dong Yun MD, PhD, Ya-yi Xia MD, PhD
}

Received: 15 June 2014/ Accepted: 30 April 2015/Published online: 16 May 2015

(C) The Association of Bone and Joint Surgeons \& 2015

\begin{abstract}
Background Arthroplasty has been shown to be superior regarding low risk of reoperation and better function score to internal fixation for treatment of displaced femoral neck fractures at short-term followup. However, there are unanswered questions regarding the efficacy of arthroplasty in the longer term compared with internal fixation.

Questions/purposes We performed a meta-analysis comparing arthroplasty (hemiarthroplasty or THA) with internal fixation in patients with displaced femoral neck fractures with respect to (1) mortality, (2) reoperation, (3) functional recovery, and (4) complications, including only randomized trials with a minimum of 4 years followup.
\end{abstract}

Each author certifies that he or she, or a member of his or her immediate family, has no funding or commercial associations (eg, consultancies, stock ownership, equity interest, patent/licensing arrangements, etc) that might pose a conflict of interest in connection with the submitted article.

All ICMJE Conflict of Interest Forms for authors and Clinical Orthopaedics and Related Research ${ }^{\mathbb{R}}$ editors and board members are on file with the publication and can be viewed on request. This study was performed at The Second Hospital of Lanzhou University, Lanzhou, China.

J. Jiang, C. Yang, X. Yun, Y. Xia ( $\square)$

Orthopaedics Key Laboratory of Gansu Province, Department of Orthopaedics, The Second Hospital of Lanzhou University,

No. 82 Cuiyingmen, Chengguan District, Lanzhou 730030, Gansu, China

e-mail: xiayayilzu@126.com; xiayayi@126.com

C. Yang

The Hand and Foot Surgery Hospital of Tianshui City, Tianshui, Gansu, China

Q. Lin

The First Clinical Medical College of Lanzhou University, Lanzhou, Gansu, China
Methods Computerized databases, including PubMed (MEDLINE), EMBASE, Cochrane Register of Controlled Trials databases, and Web of Science ${ }^{\mathrm{TM}}$ were searched for studies published from the inception date for each database to March 2014. Eleven randomized controlled trials that compared arthroplasty (either hemiarthroplasty or THA) with internal fixation for treatment of patients with a femoral neck fracture were included in our analysis. The quality of the trials was assessed according to the Cochrane Handbook and meta-analyses were conducted using RevMan 5.2 software from the Cochrane Collaboration. The heterogeneity among studies was evaluated by the I-squared index $\left(\mathrm{I}^{2}\right)$ and publication bias was assessed using forest plots.

Results There were no differences between the internal fixation and arthroplasty groups for patient mortality at midterm (48.4\% vs $46.8 \%)$ or long-term followup (83.2\% vs $81.5 \%)$. Arthroplasty was associated with a lower risk of reoperation at mid-term (7.2\% vs $39.8 \%$; relative risk $[\mathrm{RR}]=0.10 ; 95 \% \mathrm{CI}, 0.06-0.07)$ and at long-term followup $(14.3 \%$ vs $43.8 \%$; $\mathrm{RR}=0.10 ; 95 \%$ CI, $0.06-0.07)$. Arthroplasty was associated with better functional recovery at mid-term followup (standard mean difference [SMD] = $0.55 ; 95 \% \mathrm{CI}, 0.02-1.09$ ), whereas function at long-term followup (SMD $=0.14 ; 95 \% \mathrm{CI},-0.35$ to 0.62 ) was not different between the arthroplasty and internal fixation groups. There were no significant differences in subsequent ipsilateral fractures $(1.5 \%$ vs $1.2 \%$; $\mathrm{RR}=2.18 ; 95 \% \mathrm{CI}$, $0.32-14.67 ; \mathrm{p}=0.42)$ and deep infections $(2.7 \%$ vs $2.9 \%$; $\mathrm{RR}=0.89 ; 95 \% \mathrm{CI}, 0.40-2.01 ; \mathrm{p}=0.78$ ) between patients treated with arthroplasty and internal fixation.

Conclusions Based on our results, we found that compared with internal fixation, arthroplasty may result in a lower rate of subsequent reoperation at mid- and long-term followup, and better mid-term functional recovery. Future 
studies should investigate the mid- and long-term results of THAs compared with hemiarthroplasty.

\section{Introduction}

Hip fractures often are related to osteoporosis in older patients [20]. Every year, approximately 1.6 million people worldwide sustain hip fractures. A hip fracture in an older patient is a life-changing event and the risks of disability, increased dependence, and death are substantial [24]. Each year hip fractures are responsible for the loss of at least 2.35 million disability-adjusted life years and more than 5 million people worldwide experience disability from a hip fracture [7].

Established treatments for patients with femoral neck fractures-which account for almost 50\% of all hip fractures [22]—differ greatly throughout the world. For young and active patients with good bone quality, treatment using reduction with internal fixation is common. In the elderly, surgical treatment options consist of internal fixation and arthroplasty [15]. Despite increasing data on femoral neck fractures [5], the optimal treatment for elderly patients with displaced femoral neck fractures is debatable.

A meta-analysis [8] assessing short-term followup concluded that arthroplasty was superior to internal fixation for treatment of patients with femoral neck fractures. However, it is unclear whether arthroplasty leads to better function, lower reoperation rate, and fewer complications in the long term [11]. Although there are some studies at longer term [20], including reporting results into the second decade [15], these series did not find differences between internal fixation and arthroplasty in terms of mortality. However, a meta-analysis might allow pooling of the data, which could increase the likelihood that smaller but potentially important clinical differences could be detected between treatments than is possible in individual trials.

We therefore sought to perform a meta-analysis comparing arthroplasty (hemiarthroplasty or THA) with internal fixation in patients with displaced femoral neck fractures with respect to (1) mortality, (2) reoperation, (3) functional recovery, and (4) complications, including only randomized trials with a minimum of 4 years followup.

\section{Methods}

Our study was conducted in accordance with the Preferred Reporting Items for Systematic Reviews and MetaAnalyses (PRISMA) statement [13].

We systematically searched PubMed (1966 to March 2014), EMBASE (1974 to March 2014), the Cochrane
Central Register of Controlled Trials (Issue 3, 2014), and Web of Science ${ }^{\mathrm{TM}}$ (1950 to March 2014) from inception to March 2014, without date, geographic, or language limitations. We used the following search terms: "arthroplasty", "prosthetic replacement", "internal fixation", "femoral neck fractures", and "randomised controlled trials". Additionally, relevant articles, abstracts, and review articles were selected and reviewed, and the reference lists from these sources were searched for additional articles. We considered studies in which either THA or hemiarthroplasty were performed in the "arthroplasty" group. We did subanalyze to see whether there were differences between the THA and hemiarthroplasty subcohorts. All processes were performed by two reviewers (JJ, CHY) independently. The electronic database searches identified 301 citations. After evaluating the citations and reviewing articles and the bibliographies of the included studies, 11 studies [3-6, 10, 12, 14, 16-18, 21] involving 2299 patients were included for our meta-analysis (Fig. 1).

Two reviewers (XDY, YYX) independently assessed the studies and deemed them eligible if they met the following criteria: (1) randomized controlled trials (RCTs) comparing arthroplasty with internal fixation; (2) trials with at least 4 years of followup; (3) including patients with displaced fracture of the femoral neck (Garden Stage III or IV); and (4) reporting at least one of the following main clinical outcomes: reoperations for any cause, mortality, hip function score, and hip complications (dislocations, deep infections). All included studies were published in the English language and were performed in Europe. Sample sizes ranged from 100 to 455 cases with a mean followup of 9.9 years (range, 4-17 years). Based on the 11 studies that met all our criteria, 2299 patients were available for analysis. Of these, 1124 patients had an arthroplasty and 1175 patients had internal fixation (Table 1).

Primary outcomes of our meta-analysis were mortality rate and reoperation rate. Secondary outcomes included function scores and hip complications, including dislocation, periprosthetic fractures, and deep infection. Two authors (JJ and QL) independently extracted the following information from each study: year of publication, study design, number of patients, fracture classification, mean patient age, sex distribution, and mean length of followup. Inconsistencies in the extracted data were settled by consensus among all authors. As the followup time in each trial was different, the 11 trials were divided according to length of followup: midterm results ( 4 to 6 years) and long-term results (10 to 17 years). Of the studies included in our analysis, none reported results between 6 and 10 years.

Two reviewers (CHY and XDY) independently assessed the methodology of the selected articles, according to the guidelines in the Cochrane Handbook for Systematic Reviews of Interventions, version 5.1 [9]. The domains we 


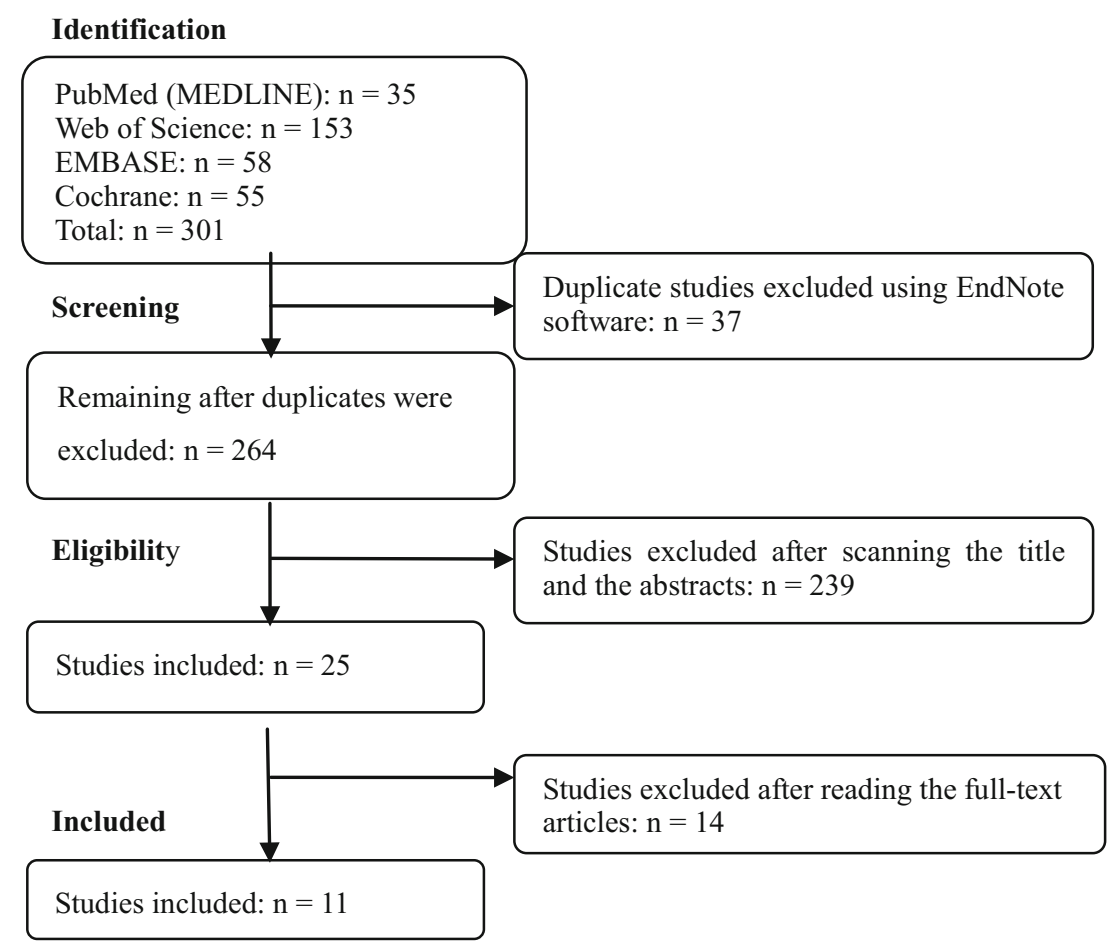

Fig. 1 A flow chart of the literature screening we used for this study is shown.

assessed were: random sequence generation, allocation concealment, blinding, incomplete outcome data, selective reporting, and other sources of bias. The reviewers resolved disagreements by discussion, and differences were reconciled by a third reviewer (YYX). All 11 studies were randomized; 10 of the studies had concealment of allocation, whereas only one study [14] did not. Three studies [3, $6,14]$ used a blinded outcome assessor, whereas in the remaining eight studies, the outcome assessor was not blinded. Each study had specified entry criteria and defined outcome measures (Table 2).

All statistical analyses were performed using Review Manager (RevMan) software, version 5.2 (The Nordic Cochrane Centre, The Cochrane Collaboration, 2012; Copenhagen, Denmark). For dichotomized outcomes, such as patient mortality or reoperation, we calculated the relative risk (RR) and corresponding 95\% CI using the number of events and total number of participants in each treatment arm. For continuous data hip function score (The Harris or Charnley hip scores), we calculated and pooled using standard mean difference (SMD). To assess heterogeneity, we used the $\mathrm{I}^{2}$ statistic. In analyses in which heterogeneity was low $\left(\mathrm{I}^{2}<50 \%\right)$, a fixed-effects model was used; otherwise, a random-effects model was used. A funnel plot based on the primary outcome was used to evaluate publication bias.

\section{Results}

We found no differences in patient mortality at mid-term $(46.8 \%$ vs $48.4 \% ; \quad \mathrm{RR}=0.91 ; 95 \% \quad \mathrm{CI}, \quad 0.76-1.10$; $\mathrm{p}=0.62]$ compared with long-term $(81.5 \%$ vs $83.2 \%$; $\mathrm{RR}=0.85 ; 95 \% \mathrm{CI}, 0.64-1.12 ; \mathrm{p}=0.36)$ between the two groups. There was no significant heterogeneity $\left(p=0.62 ; I^{2}=0 \%\right)$ between studies, so we used a fixedeffect model for the meta-analysis of mortality. Data regarding patient mortality at mid-term and long-term followups were provided in nine studies $[3,5,6,12,14$, 16-18, 21] involving 1033 patients (Table 3). Subgroup analysis showed that there was no difference in comparison of either THA or hip arthroplasty with internal fixation at mid- and long-term followups (Table 4). The result for publication bias using the mortality rate revealed that there was publication bias among the included studies.

Arthroplasty was associated with a lower risk of subsequent reoperations at mid-term $(7.2 \%$ vs $39.8 \%$; $\mathrm{RR}=0.10 ; 95 \% \mathrm{CI}, 0.06-0.07 ; \mathrm{p}=0.09)$ and at longterm $(14.3 \%$ vs $43.8 \%$; $\mathrm{RR}=0.22$; $95 \% \mathrm{CI}, 0.11-0.43$; $\mathrm{p}=0.003]$ compared with internal fixation. Substantial heterogeneity was observed $\left(\mathrm{p}<0.01 ; \mathrm{I}^{2}=69 \%\right)$, so we used a random-effect model here. Eleven studies reported reoperation rates at mid- and long-term followups [3-6, 10, 12, 14, 16-18, 21] (Table 3). Subgroup analysis revealed 


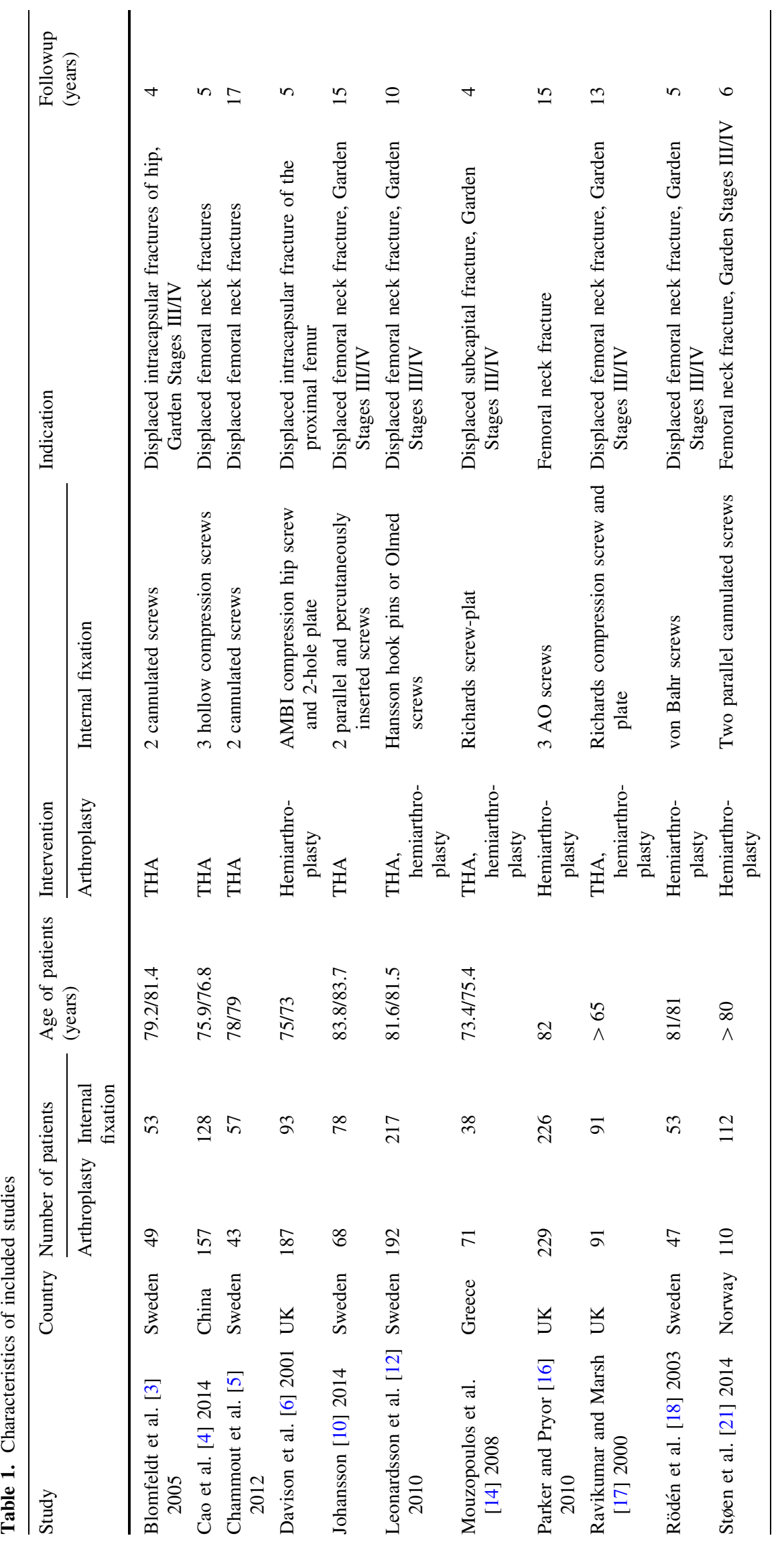


Table 2. Risk of bias in included studies

\begin{tabular}{|c|c|c|c|c|c|c|}
\hline Study & Randomization & $\begin{array}{l}\text { Allocation } \\
\text { concealment }\end{array}$ & Blinding & $\begin{array}{l}\text { Incomplete } \\
\text { outcome data }\end{array}$ & $\begin{array}{l}\text { Selective } \\
\text { reporting }\end{array}$ & Other bias \\
\hline Blomfeldt et al. [3] & $\mathrm{RCT}$ & Sealed envelope & Yes & No & Unclear & Unclear \\
\hline Cao et al. [4] & $\mathrm{RCT}$ & Sealed envelope & Unclear & No & Unclear & Unclear \\
\hline Chammout et al. [5] & $\mathrm{RCT}$ & Sealed envelope & Unclear & No & Unclear & Unclear \\
\hline Davison et al. [6] & RCT & Sealed envelope & Yes & No & Unclear & Unclear \\
\hline Johansson [10] & $\mathrm{RCT}$ & Sealed envelope & Unclear & No & Unclear & Unclear \\
\hline Leonardsson et al. [12] & $\mathrm{RCT}$ & Sealed envelope & Unclear & No & Unclear & Unclear \\
\hline Mouzopoulos et al. [14] & $\mathrm{RCT}$ & No & Yes & No & Unclear & Unclear \\
\hline Parker et al. [16] & $\mathrm{RCT}$ & Sealed envelope & Unclear & No & Unclear & Unclear \\
\hline Ravikumar and Marsh [17] & $\mathrm{RCT}$ & Sealed envelope & Unclear & No & Unclear & Unclear \\
\hline Rödén et al. [18] & $\mathrm{RCT}$ & Sealed envelope & Unclear & No & Unclear & Unclear \\
\hline Støen et al. [21] & $\mathrm{RCT}$ & Sealed envelope & Unclear & No & Unclear & Unclear \\
\hline
\end{tabular}

$\mathrm{RCT}=$ randomized controlled trial.

Table 3. Outcomes of study meta-analysis

\begin{tabular}{|c|c|c|c|c|c|c|}
\hline \multirow[t]{2}{*}{ Patient outcome } & \multirow{2}{*}{$\begin{array}{l}\text { Included studies } \\
\text { (reference number) }\end{array}$} & \multicolumn{2}{|c|}{ Number of patients $(\mathrm{n} / \mathrm{N})$} & \multirow[t]{2}{*}{$\mathrm{SMD}^{\dagger}$ or $\mathrm{RR}(95 \% \mathrm{CI})$} & \multirow[t]{2}{*}{$\mathrm{p}$ value } & \multirow{2}{*}{$\begin{array}{l}\text { Heterogenicity } \\
\left(\mathrm{I}^{2}=\%\right)\end{array}$} \\
\hline & & Arthroplasty & Internal fixation & & & \\
\hline \multicolumn{7}{|l|}{ Mortality } \\
\hline Mid-term & {$[3,5,6,12,14,16,17,21]$} & $441 / 943$ & $479 / 990$ & $0.91(0.76-1.10)$ & 0.35 & 0 \\
\hline Long term & {$[5,12,16,18]$} & $560 / 687$ & $615 / 739$ & $0.85(0.64-1.12)$ & 0.25 & 8 \\
\hline \multicolumn{7}{|l|}{ Reoperation } \\
\hline Mid-term & {$[3,4,6,14,16,17,21]$} & $62 / 865$ & $336 / 844$ & $0.12(0.07-0.19)$ & 0.001 & 53 \\
\hline Long term & {$[5,10,12,18]$} & $69 / 483$ & $234 / 534$ & $0.22(0.11-0.43)$ & 0.001 & 75 \\
\hline \multicolumn{7}{|l|}{ Function score } \\
\hline Mid-term & {$[3,5,14,21]$} & 149 & 146 & $0.55^{\dagger}(0.02-1.09)$ & 0.04 & 79 \\
\hline Long term & {$[5,18]$} & 202 & 203 & $0.14^{\dagger}(-0.35$ to 0.62$)$ & 0.59 & 76 \\
\hline \multicolumn{7}{|l|}{ Dislocation } \\
\hline Mid-term & {$[12,16]$} & $11 / 421$ & $2 / 443$ & $3.28(0.06-192.16)$ & 0.57 & 79 \\
\hline Long term & {$[5,10,18]$} & $51 / 291$ & $1 / 317$ & $25.86(7.09-94.34)$ & 0.001 & 0 \\
\hline \multicolumn{7}{|l|}{ Deep infection } \\
\hline Mid-term & {$[4]$} & $5 / 157$ & $2 / 128$ & $2.07(0.40-10.86)$ & 0.39 & Not provided \\
\hline Long term & {$[5,12,18]$} & $11 / 415$ & $13 / 456$ & $0.89(0.40-2.01)$ & 0.78 & 0 \\
\hline \multicolumn{7}{|c|}{ Subsequent ipsilateral fractures } \\
\hline Mid-term & {$[3,10,16]$} & $7 / 470$ & $6 / 496$ & $1.67(0.16-16.95)$ & 0.66 & 60 \\
\hline Long term & {$[5]$} & $2 / 43$ & $0 / 57$ & $6.93(0.32-148.12)$ & 0.22 & Not provided \\
\hline
\end{tabular}

$\mathrm{RR}=$ relative risk; $\mathrm{SMD}^{\dagger}=$ standard mean difference $\mathrm{n}=$ number of patients with clinical symptoms; $\mathrm{N}=$ total number of patients

that there were fewer reoperations in patients treated by either THA or hemiarthroplasty than by internal fixation at mid-term followup (Table 4).

Function was higher at mid-term $(\mathrm{SMD}=0.55 ; 95 \%$ CI, 0.02-1.09; $\mathrm{p}=0.04)$ in patients treated with arthroplasty than in those treated with internal fixation, with no differences found at long-term followup ( $\mathrm{SMD}=0.14$; $95 \% \mathrm{CI},-0.35$ to $0.62 ; \mathrm{p}=0.04)$. There was significant heterogeneity $\left(\mathrm{p}<0.01 ; \mathrm{I}^{2}=77 \%\right)$ among studies, so we used a random-effect model for this analysis. Five studies $[3,5,14,17,21]$, with a total of 677 patients provided patient function outcomes at mid-term and long-term postoperatively. Subgroup analysis showed that function outcome was superior in patients treated with either THA or hemiarthroplasty than for patients treated by internal fixation (Table 4).

There were no differences in subsequent ipsilateral fractures $(\mathrm{RR}=2.18 ; 95 \% \mathrm{CI}, 0.32-14.67 ; \mathrm{p}=0.42)$ and 
Table 4. Subgroup analysis of main outcomes

\begin{tabular}{|c|c|c|c|c|c|c|}
\hline \multirow[t]{2}{*}{ Outcomes } & \multirow{2}{*}{$\begin{array}{l}\text { Included } \\
\text { studies }\end{array}$} & \multicolumn{2}{|c|}{ Number of patients $(\mathrm{n} / \mathrm{N})$} & \multirow{2}{*}{$\begin{array}{l}\mathrm{SMD}^{\dagger} \text { or } \mathrm{RR} \\
(95 \% \mathrm{CI})\end{array}$} & \multirow[t]{2}{*}{$\mathrm{p}$ value } & \multirow{2}{*}{$\begin{array}{l}\text { Heterogeneity } \\
\left(\mathrm{I}^{2}=\%\right)\end{array}$} \\
\hline & & Arthroplasty & Internal fixation & & & \\
\hline \multicolumn{7}{|c|}{ Mortality at mid-term } \\
\hline THA & {$[3,5]$} & $20 / 92$ & $28 / 110$ & $0.81(0.4-1.56)$ & 0.53 & 0 \\
\hline Hemiarthroplasty & {$[6,16,17,21]$} & $297 / 573$ & $323 / 577$ & $0.83(0.65-1.06)$ & 0.13 & I0 \\
\hline \multicolumn{7}{|c|}{ Mortality at long term } \\
\hline THA & {$[5]$} & $60 / 86$ & $90 / 114$ & $0.60(0.3-1.16)$ & 0.13 & $\mathrm{I} 20$ \\
\hline Hemiarthroplasty & {$[16]$} & $206 / 229$ & $199 / 226$ & $1.22(0.67-2.19)$ & 0.52 & Not provided \\
\hline \multicolumn{7}{|c|}{ Reoperation at mid-term } \\
\hline THA & {$[3,4]$} & $18 / 206$ & $68 / 181$ & $0.12(0.03-0.55)$ & $<0.01$ & 33 \\
\hline Hemiarthroplasty & {$[6,16,17,21]$} & $38 / 573$ & $250 / 577$ & $0.09(0.06-0.13)$ & $<0.01$ & 1 \\
\hline \multicolumn{7}{|c|}{ Reoperation at long term } \\
\hline THA & {$[5,10]$} & $25 / 111$ & $75 / 135$ & $0.22(0.13-0.40)$ & $<0.01$ & I0 \\
\hline \multicolumn{7}{|c|}{ Function score at mid-term } \\
\hline THA & {$[3,5]$} & 69 & 78 & $0.21^{\dagger}(-0.12$ to 0.53$)$ & 0.21 & 0 \\
\hline Hemiarthroplasty & {$[21]$} & 37 & 30 & $0.00^{\dagger}(-0.48$ to 0.48$)$ & 1.00 & Not provided \\
\hline \multicolumn{7}{|c|}{ Function score at long term } \\
\hline THA & {$[5]$} & 22 & 21 & $0.17^{\dagger}(-0.43$ to 0.77$)$ & 0.58 & Not provided \\
\hline
\end{tabular}

$\mathrm{RR}=$ relative risk; $\mathrm{SMD}^{\dagger}=$ standard mean difference; $\mathrm{n}=$ number of patients with clinical symptoms; $\mathrm{N}=$ total number of patients.

deep infections $(\mathrm{RR}=0.89 ; 95 \% \mathrm{CI}, 0.40-2.01 ; \mathrm{p}=0.78)$ between patients treated with arthroplasty and internal fixation. Substantial heterogeneity was not observed ( $\mathrm{p}=0.85 ; \mathrm{I}^{2}=0 \%$ ), so we used a fixed-effects model for the meta-analysis of complications. Six studies [3, 5, 10, $12,16,17]$ with a total of 1372 patients covered major complications.

\section{Discussion}

The best treatment for patients with displaced femoral neck fractures is debatable. Evidence from a meta-analysis [8] showed short-term results of arthroplasty to be superior to those of internal fixation. However, long-terms results of arthroplasty compared with results of internal fixation remain controversial [3, 5, 6, 10, 12, 19, 21].We therefore compared mid- and long-term results after arthroplasty or internal fixation in patients with femoral neck fractures. Eleven RCTs that reported outcomes with at least 4 years of followup were identified. The most important findings of our study were that arthroplasty was associated with a lower risk of subsequent reoperations at mid- and longterm followups. In terms of complications, there were no differences in frequency of infection between the groups, and some patients treated with arthroplasty had dislocations, and some with internal fixation had nonunions and osteonecrosis develop.

There were some limitations to our study. First, the methodologic quality of the included studies was not optimal, although only RCTs were included in our analysis. For instance, only three studies [3, 6, 14] used blinding. The result of a funnel plot for mortality rate showed there was publication bias among studies; this might because only English-language studies were included. Second, the type of arthroplasty (hemiarthroplasty or total arthroplasty, cemented or uncemented) and internal fixation methods (screws versus other) may have had an effect on the final treatment, although the subgroup analysis based on THA or hemiarthroplasty was conducted. Third, high mortality was found in the internal fixation group, therefore potential risk factors should be examined in the future studies. Finally, there was a paucity of data regarding time from injury to definitive treatment, which would be important in avoiding complications such as osteonecrosis in an open reduction and internal fixation or venous thromboembolism with an arthroplasty. Only one study [5] reported the delay in the group with open reduction and internal fixation, with two of 93 patients who had open reduction and internal fixation receiving delayed surgical treatment.

Regarding mortality, our meta-analysis showed that at mid- and long-term followups, the patient mortality rate did not differ between patients who had arthroplasty or internal fixation. Some studies [2, 12] with short-term followup showed that a statistically significant incremental trend in risk of death occurred after arthroplasty compared with the risk during short-term followup after internal fixation. However, long-term results [5, 10, 21] showed no difference in mortality rates between arthroplasty and internal fixation in patients treated for displaced femoral neck 
fractures. In our meta-analysis, we found no difference in patient mortality between the two procedures at mid- and long-term followups.

Regarding reoperation, our meta-analysis revealed that arthroplasty decreased patient risk of reoperation compared with internal fixation at mid- and long-term followups. Internal fixation provides the possibility of retaining the native hip, but clinical failure resulting in reoperation occurs in approximately $1 / 3$ of patients with displaced femoral neck fractures treated with internal fixation [23]. The percentages of patients undergoing reoperations at mid- and long-term followups in our meta-analysis were $6.5 \%(62 / 865)$ and $14.3 \%(69 / 483)$ in the arthroplasty group, and $39.8 \%(336 / 844)$ and $43.8 \%(234 / 534)$ in the internal fixation group, respectively, results which are similar to those of previous studies $[5,12,17]$. In a randomized trial with a followup of 13 years, Ravikumar and Marsh [17] found that arthroplasty reduced long-term risks, which likely is attributable to greater mortality in patients 65 years or older with femoral neck fractures.

Another important clinical outcome was function score. Our study showed that patients treated with arthroplasty had better function recovery than those treated with internal fixation at mid-term, whereas we found no difference in function between treatment groups at long-term followup. With less patient pain and low reoperation rates, arthroplasty was thought to be a more restorative and costeffective procedure than internal fixation [8]. A previous short-term study [8] showed that function was superior for patients treated with arthroplasty than for patients treated with internal fixation; however, the long-term results of our meta-analysis revealed that arthroplasty provided similar functional outcomes compared with internal fixation.

In addition, arthroplasty often was associated with an assumed risk of long-term complications, such as periprosthetic fracture and aseptic loosening [21]. In our meta-analysis, we found that arthroplasty was associated with a greater risk of hip dislocation at long-term followup, which was consistent with results of previous studies [5, $10,12,17]$, whereas higher risk of nonunion and avascular osteonecrosis were found in the internal fixation group at mid- and long-term followups. More importantly, our study showed that there were no differences in deep infections and subsequent ipsilateral fractures between groups, which was different with meta-analysis of short-term results [25].

Subgroup analysis based on THA or hemiarthroplasty showed no differences with respect to mortality rate and function score between either THA or hemiarthroplasty compared with internal fixation, except for reoperation rate. The mid- to long-term results of THA compared with hemiarthroplasty rarely were reported. Avery et al. [1] reviewed the 7- to 10-year results of THA compared with hemiarthroplasty for fracture of the femoral neck and reported lower mortality and a trend toward superior function in patients with THA. Future studies comparing THA with hemiarthroplasty at long-term followup are needed to confirm these results.

Our meta-analysis of 11 RCTs with 2299 patients suggests that treatment with arthroplasty results in lower risk of reoperation and better function outcomes than use of internal fixation at mid-term and long-term followups, despite higher dislocation rates associated with arthroplasty. Well-designed randomized clinical studies with long-term followups are needed to confirm our results. In addition, future studies should be designed to determine which type of arthroplasty (total or hemiarthroplasty, cemented or uncemented) is better.

\section{References}

1. Avery PP, Baker RP, Walton MJ, Rooker JC, Squires B, Gargan MF, Bannister GC. Total hip replacement and hemiarthroplasty in mobile, independent patients with a displaced intracapsular fracture of the femoral neck: a seven- to ten-year follow-up report of a prospective randomised controlled trial. J Bone Joint Surg Br. 2011;93:1045-1048.

2. Bhandari M, Devereaux PJ, Swiontkowski MF, Tornetta P, Obremskey W, Koval KJ, Nork S, Sprague S, Schemitsch EH, Guyatt GH. Internal fixation compared with arthroplasty for displaced fractures of the femoral neck: a meta-analysis. $J$ Bone Joint Surg Am. 2003;85:1673-1681.

3. Blomfeldt R, Tornkvist H, Ponzer S, Soderqvist A, Tidermark J. Comparison of internal fixation with total hip replacement for displaced femoral neck fractures: randomized, controlled trial performed at four years. J Bone Joint Surg Am. 2005;87:1680-1688.

4. Cao L, Wang B, Li M, Song S, Weng W, Li H, Su J. Closed reduction and internal fixation versus total hip arthroplasty for displaced femoral neck fracture. Chin J Traumatol. 2014;17:63-68.

5. Chammout GK, Mukka SS, Carlsson T, Neander GF, Stark AW, Skoldenberg OG. Total hip replacement versus open reduction and internal fixation of displaced femoral neck fractures: a randomized long-term follow-up study. J Bone Joint Surg Am. 2012;94:1921-1928.

6. Davison JN, Calder SJ, Anderson GH, Ward G, Jagger C, Harper WM, Gregg PJ. Treatment for displaced intracapsular fracture of the proximal femur: a prospective, randomised trial in patients aged 65 to 79 years. J Bone Joint Surg Br. 2001;83:206-212.

7. Frihagen F, Nordsletten L, Madsen JE. Hemiarthroplasty or internal fixation for intracapsular displaced femoral neck fractures: randomised controlled trial. BMJ. 2007;335:1251-1254.

8. Gao H, Liu Z, Xing D, Gong M. Which is the best alternative for displaced femoral neck fractures in the elderly?: a meta-analysis. Clin Orthop Relat Res. 2012;470:1782-1791.

9. Higgins. JP, Green S. Cochrane Handbook for Systematic Reviews of Interventions Version 5.1.0 [updated March 2011]. The Cochrane Collaboration. Available at: www.cochrane-handbook. org/. Accessed February 2, 2012.

10. Johansson $T$. Internal fixation compared with total hip replacement for displaced femoral neck fractures: a minimum fifteenyear follow-up study of a previously reported randomized trial. $J$ Bone Joint Surg Am. 2014;96:e46.

11. Kim YS, Kim YH, Hwang KT, Choi IY. The cartilage degeneration and joint motion of bipolar hemiarthroplasty. Int Orthop. 2012;36:2015-2020. 
12. Leonardsson O, Sernbo I, Carlsson A, Akesson K, Rogmark C. Long-term follow-up of replacement compared with internal fixation for displaced femoral neck fractures: results at ten years in a randomised study of 450 patients. J Bone Joint Surg Br. 2010;92:406-412.

13. Moher D, Liberati A, Tetzlaff J, Altman DG; PRISMA Group. Preferred reporting items for systematic reviews and meta-analyses: the PRISMA statement. J Clin Epidemiol. 2009;62:1006-1012.

14. Mouzopoulos G, Stamatakos M, Arabatzi H, Vasiliadis G, Batanis G, Tsembeli A, Tzurbakis M, Safioleas M. The four-year functional result after a displaced subcapital hip fracture treated with three different surgical options. Int Orthop. 2008;32:367-373.

15. Murphy DK, Randell T, Brennan KL, Probe RA, Brennan ML. Treatment and displacement affect the reoperation rate for femoral neck fracture. Clin Orthop Relat Res. 2013;471:2691-2702.

16. Parker MJ, Pryor G, Gurusamy K. Hemiarthroplasty versus internal fixation for displaced intracapsular hip fractures: a longterm follow-up of a randomised trial. Injury. 2010;41:370-373.

17. Ravikumar KJ, Marsh G. Internal fixation versus hemiarthroplasty versus total hip arthroplasty for displaced subcapital fractures of femur: 13 year results of a prospective randomised study. Injury. 2000;31:793-797.

18. Rödén M, Schön M, Fredin H. Treatment of displaced femoral neck fractures: a randomized minimum 5-year follow-up study of screws and bipolar hemiprostheses in 100 patients. Acta Orthop Scand. 2003;74:42-44.
19. Rogmark C. CORR Insights ${ }^{\mathbb{R}}$ : Randomized trial of hemiarthroplasty versus internal fixation for femoral neck fractures: no differences at 6 years. Clin Orthop Relat Res. 2014;472: 368-369.

20. Sterling RS. Gender and race/ethnicity differences in hip fracture incidence, morbidity, mortality, and function. Clin Orthop Relat Res. 2011;469:1913-1918.

21. Stoen RO, Lofthus CM, Nordsletten L, Madsen JE, Frihagen F. Randomized trial of hemiarthroplasty versus internal fixation for femoral neck fractures: no differences at 6 years. Clin Orthop Relat Res. 2014;472:360-367.

22. Stoen RO, Nordsletten L, Meyer HE, Frihagen JF, Falch JA, Lofthus CM. Hip fracture incidence is decreasing in the high incidence area of Oslo, Norway. Osteoporos Int. 2012;23:2527-2534.

23. Tidermark J, Ponzer S, Svensson O, Soderqvist A, Tornkvist H. Internal fixation compared with total hip replacement for displaced femoral neck fractures in the elderly: a randomised, controlled trial. J Bone Joint Surg Br. 2003;85:380-388.

24. van Balen R, Steyerberg EW, Polder JJ, Ribbers TL, Habbema JD, Cools HJ. Hip fracture in elderly patients: outcomes for function, quality of life, and type of residence. Clin Orthop Relat Res. 2001;390:232-243.

25. Wang J, Jiang B, Marshall RJ, Zhang P. Arthroplasty or internal fixation for displaced femoral neck fractures: which is the optimal alternative for elderly patients? A meta-analysis. Int Orthop. 2009;33:1179-1187. 